\title{
Under- and Over-Nutrition Among Refugees in San Diego County, California
}

\author{
Amanda J. Rondinelli • Meghan D. Morris • \\ Timothy C. Rodwell $\cdot$ Kathleen S. Moser • \\ Paulino Paida $\cdot$ Steve T. Popper $\cdot$ Kimberly C. Brouwer
}

Published online: 27 May 2010

(C) The Author(s) 2010. This article is published with open access at Springerlink.com

\begin{abstract}
Resettled refugees often arrive in their host country with little knowledge of nutrition or available food choices. We explored nutrition-related issues of recent refugee arrivals to San Diego County-the second largest California resettlement site. In-depth interviews $(n=40)$ were conducted with refugees, health care practitioners, and refugee service organizations. Content analysis identified nutrition-related themes. Unhealthy weight gain after arrival was the most common concern and was attributed to social pressures among adolescents, food choices and a more sedentary lifestyle. Conversely, undernutrition remained a concern due to poor diets. Factors influencing nutritional problems included continuation of past habits, acculturation, unfamiliarity with available foods and socioeconomic influences. The nutritional concerns encountered by resettled refugees in San Diego are not unique to this group but are aggravated by their past experiences, and abrupt changes to food choices and behavior. Addressing contextual factors of poor food choices may prevent some of the long term health consequences of poor nutrition.
\end{abstract}

A. J. Rondinelli - M. D. Morris · T. C. Rodwell ·

S. T. Popper · K. C. Brouwer $(\square)$

Department of Medicine, University of California San Diego

School of Medicine, 9500 Gilman Drive, Mailcode 0507,

San Diego, La Jolla, CA 92093-0507, USA

e-mail: kbrouwer@ucsd.edu

K. S. Moser · P. Paida

County of San Diego Health and Human Services Agency,

San Diego, CA, USA
Keywords Refugee - Nutrition · Overweight . Malnutrition

\section{Introduction}

A refugee is defined as "a person who is unable or unwilling to return to his or her country of nationality because of persecution on account of race, religion, nationality, membership in a particular social group, or political opinion [1]." In 2007, 67 million people worldwide were forcibly displaced from their native country due to war or political persecution, over 16 million were classified as refugees living outside their native country, and 75,000 were admitted to fourteen countries for permanent resettlement [2]. The United States was the largest resettlement site, admitting $64 \%$ of this total plus an additional 25,000 asylum-seekers $[1,2]$. California resettled more refugees and asylees in 2007 than any other US state, and San Diego County was the second largest resettlement site in California [1,3].

Much has been reported on the nutritional status of refugees prior to and immediately post-resettlement [4-7], but refugee nutrition in subsequent years remains understudied. Upon arrival in the host country, most refugees receive a health assessment, which may or may not include a physical exam, to assess primarily infectious disease risks [8]. Nutritional issues are seldom included in the assessment despite the fact that under- and over-nutrition can contribute to a variety of often preventable long-term health consequences $[8,9]$.

We conducted a general health needs assessment by performing guided in-depth interviews among community members who were knowledgeable about health issues faced by recently resettled refugees in San Diego, California. The current analysis, the first of its kind in this 
region, was performed to explore nutrition-related health concerns associated with resettlement.

\section{Methods}

\section{Study Population}

Detailed study methods were reported previously [10]. Briefly, between December 2006 and March 2007, participants were recruited in San Diego County using targeted sampling methods. Participants included: (a) refugees who resettled in the U.S. one to five years prior to data collection $(n=16)$, which is the period after which government assistance has usually ended and during which service providers in San Diego consider refugees to be particularly vulnerable due to lack of financial establishment and knowledge of the host country [11]; (b) one representative from each of the four voluntary resettlement agencies (VOLAGs) in San Diego County $(n=4)$; (c) personnel of mutual assistance agencies (MAAs), which are non-profit community-based organizations with at least $51 \%$ of their governing board comprised of resettled refugees $(n=10)$; and (d) health care providers (HCPs) with a large refugee clientele base $(n=10)$.

\section{Sampling}

In qualitative research, the sampling strategy goal is to reflect a diversity of viewpoints, rather than a statistical representation of the population. The minimum number of interviews on a subject needed to identify major themes on an issue is generally agreed to be 15-20 [12]. By conducting 40 interviews, we anticipated identifying most major nutrition-related issues. Participating organizations were selected from a list of 111 refugee serving organizations in San Diego County, which included VOLAGs, MAAs, and health care providers. This list was created by combining information from several sources [10] and validated through a brief phone survey. MAAs were categorized by primary population served (e.g., Somalis) prior to selection and randomly sampled when more than one organization served a particular group. VOLAG and MAA participants were recommended by their respective agency, based on the assessment objectives. For health care providers $(n=10)$, several large clinics whose catchment area largely consisted of refugees were targeted, with the remaining being from health clinics randomly selected from a list of health care providers identified as commonly serving refugees. Sampling of refugee informants $(n=16)$ was stratified to include one male and one female from each of the eight countries contributing the greatest numbers of refugees in San Diego: Afghanistan (6\%), Ethiopia
$(6 \%)$, Iran (7\%), Iraq (15\%), Russia (4\%), Somalia (27\%), Sudan (7\%), and Vietnam (8\%) [3]. Refugee recruitment occurred through referrals from MAAs, VOLAGs, and personnel connected with specific refugee communities who were familiar with project aims. In particular, we requested that they recruit key stakeholders in the community, such as community leaders familiar with health concerns within their community. VOLAG, MAA, and HCP participants were expected to have knowledge of the health needs of the San Diego refugee community through direct relationships with resettled refugees. Only one refugee participant who was referred to the study refused to participate, due to lack of availability.

\section{Data Collection}

The United Nations definition of a refugee was summarized at the start of each interview [13] and all participants, especially HCP, were reminded that responses should be focused on their refugee clientele, and not immigrants or other groups that might comprise their patient base. Furthermore, in order to continually focus responses on the resettled refugee community, most questions included terms such as "affecting refugees in San Diego," or "thinking of the refugees you serve." To gather information on quantitative variables, VOLAG, MAA and HCP participants were asked about their services and associations with refugee populations; and refugees were asked about their immigration status, and past and current residential situations.

Qualitative domains included: perceived major health conditions of resettled refugees, socio-cultural issues (e.g. cultural remedies and traditions), behaviors affecting health, and access to health care services. Because this study was designed as a general health needs assessment, no standard was provided to interviewees for terms such as "weight gain" or "obesity." However, in order to have a better understanding of what interviewees were trying to convey, interviewers were instructed to probe in regards to general clinical terms.

Interviews lasted approximately $1 \mathrm{~h}$ and were conducted by outreach workers. For most refugee interviews, trained interpreters conducted interviews in participants' native languages. Interviews were audio-taped in private locations, transcribed into text, and translated into English if needed. Participants were reimbursed \$15 USD for their time. This study was approved by the institutional review board at the University of California, San Diego and all participants provided written informed consent.

\section{Analysis}

For the current analysis, transcripts were read and coded by two investigators (AR and MM) using Atlas.ti (Atlas.ti, 
Version 5.5, Berlin, Germany) to identify emergent themes related to nutrition and nutrition-related health consequences affecting the resettled refugee population. As this study was not designed to focus on nutrition, perspectives regarding dietary issues and related health problems that were analyzed for this project were not from specific questions about obesity or nutrition. Rather, nutritional issues emerged throughout the interview process in response to general questions such as: "What are some changes in behavior that refugees have adopted while living in the United Sates that have affected their health?" or "Are there issues affecting the health of refugee children that you feel are important?" Interviewers were instructed to probe for more details on any issue that arose. In the present analysis, nutritional issues were coded to capture common themes. Consistency and agreement on emergent themes were assessed and then clarified for a subsequent round of coding. The quotations presented in the Results were selected for inclusion if they were illustrative of a recurring theme surrounding nutrition. Descriptive statistics of participants were calculated using the Statistical Package for the Social Sciences for Microsoft Windows version 13.0 (SPSS, Inc., Chicago, 2004).

\section{Results}

\section{Participant Characteristics}

Characteristics of the study population have been provided in detail elsewhere [10]. In brief, the median age of the 16 refugees interviewed was 41 (interquartile range (IQR) 3754), and median length of time in the United States was 3.0 years (IQR 1.3-4.0) (Table 1). More than half had at

Table 1 Characteristics of refugee participants $(n=16)$

\begin{tabular}{ll}
\hline Category & Number $(n=16)$ \\
\hline Gender & 8 \\
Male & \\
Age (years) & $41(37,54)$ \\
$\quad$ Median (Inter-quartile range) & \\
Highest education level completed & 4 \\
Elementary school or below & 2 \\
Middle school & 3 \\
High school & 2 \\
Trade/technical school & 1 \\
Some college & 3 \\
College grad & 1 \\
PhD/MD/JD & \\
Number of years in US & $3.0(1.3,4.0)$ \\
Median (Inter-quartile range) &
\end{tabular}

least a high school education, with $25 \%$ having obtained a college degree or higher (Table 1). The 4 VOLAG and 10 MAA representatives had been working with the refugee population a median of 7 years (IQR 4.8-19.3). The median age was $37,57 \%$ were male, and half had at least a college degree (Table 2). Almost all of the VOLAG and MAA participants were born outside of the US (93\%), 86\% had originally come to the U.S. as a refugee, and the

Table 2 Characteristics of refugee service organization and health care provider participants $(n=24)$

\begin{tabular}{|c|c|c|}
\hline Category & $\begin{array}{l}\text { VOLAG/MAA } \\
N=14\end{array}$ & $\begin{array}{l}\text { Health care } \\
\text { providers } \\
N=10\end{array}$ \\
\hline \multicolumn{3}{|l|}{ Gender } \\
\hline Male & 8 & 0 \\
\hline \multicolumn{3}{|l|}{ Age (years) } \\
\hline Median (Inter-quartile range) & $36.5(26.5,47.0)$ & $46(37.0,53.5)$ \\
\hline \multicolumn{3}{|c|}{ Highest education level completed } \\
\hline High school or below & 1 & 0 \\
\hline Some college & 6 & 1 \\
\hline College Grad & 5 & 0 \\
\hline Masters & 2 & 6 \\
\hline $\mathrm{PhD} / \mathrm{MD} / \mathrm{JD}$ & 0 & 3 \\
\hline \multicolumn{3}{|c|}{ No. years organization has served refugees } \\
\hline Median (Inter-quartile range) & $10.5(4.9,22.8)$ & $18.5(7.5,41.0)$ \\
\hline \multicolumn{3}{|l|}{ Populations often served } \\
\hline Non-refugees & 1 & 6 \\
\hline All refugees & 3 & 1 \\
\hline Vietnamese & 3 & 6 \\
\hline Sudanese & 7 & 4 \\
\hline Somalis & 9 & 5 \\
\hline Russians & 3 & 2 \\
\hline Iraqis & 3 & 1 \\
\hline Iranians & 4 & 1 \\
\hline Ethiopians & 6 & 3 \\
\hline Afghanis & 4 & 2 \\
\hline Former refugee & 12 & 1 \\
\hline \multicolumn{3}{|l|}{ Years living in the US } \\
\hline Median (Inter-quartile range) & $15(9.0-22.5)$ & - \\
\hline \multicolumn{3}{|c|}{ Country of origin of former refugees $(n=12)$} \\
\hline Albania & 1 & 0 \\
\hline Ethiopia & 2 & 0 \\
\hline Iraq & 1 & 0 \\
\hline Poland & 1 & 0 \\
\hline Somalia & 3 & 0 \\
\hline Sudan & 3 & 0 \\
\hline Vietnam & 1 & 1 \\
\hline
\end{tabular}

VOLAG Voluntary Agency that resettles incoming refugees, MAA Mutual Assistance Agency providing support to refugees during the resettlement process 
median length of time living in the US was 15 years (Table 2). All 10 health care providers (HCPs) interviewed were female with a median age of 46 years (IQR 37.053.5), and included a physician, social workers, nurses, and directors of health promotion programs (Table 2). Sixty percent had a Master's level degree and 30\% an advanced degree $(\mathrm{PhD}, \mathrm{MD}$, etc.) (Table 2). At the time of the interview, the HCPs interviewed had been personally working with the refugee population a median of 11 years (IQR 6.8-16.8).

\section{In-Depth Interviews}

Our analysis identified nutrition-related health issues faced by resettled refugees and associated influencing factors, including the influence of past habits on present nutrition, acculturation, socio-economic and neighborhood factors, and knowledge deficits.

\section{Nutrition-Related Health Concerns}

Unhealthy weight gain among resettled refugees was the nutrition-related health issue most frequently identified by participants. Some felt that the kinds of foods readily available in the US were the cause of their weight gain, or that refugees "don't pay attention to what they eat" (Refugee of African origin, 51). The quantity of food consumed was also mentioned.

Right now their fridge is full and they just eat, eat, they don't even watch. Over there [it] is really hard to find food... when you see the person when they get here they are 110lbs and a year later they are 200lbs, so that is fast. (Refugee of African origin, 33)

Rapid weight gain among refugee children was reported and thought to be due to food preferences and eating habits. A HCP described the transformation as occurring within the first five years of resettlement.

Not as they come, but after they've been here... the first year, not necessarily, the second year... we tend to think, oh people look healthier. The third year we start wondering, wow, that's a really big kid ... and then by the 4th and 5th year some of the kids are looking very chubby. (HCP, 42)

While much more concern was voiced over weight gain, more than a quarter of participants reported what they perceived to be as malnourishment and/or anemia as a problem that was still affecting refugees post-resettlement. Acknowledgement was made that refugees are seldom overweight upon arrival to the US because they "have been...living in undernourished situations like refugee camps and doing without a lot of the proper nutrition"
$(H C P, 47)$, and in some situations this remained a concern post-resettlement.

They [children] eat too much food they are not supposed to eat...they wind up of having too much lack of nutrition... and they look like they are starved because they don't feed them well. (MAA, Former Refugee, 42)

A HCP reported that traditional beliefs in regards to nutrition for babies and young children have had severe effects.

I do see like a lot of... Southeast Asian mostly, they like to do a lot of rice, they like to do a lot of milk... and that really has an effect because I see children with severe anemias sometimes, iron deficiency anemia. $(H C P, 45)$

Chronic health conditions that can be the consequence of, or exacerbated by, poor nutrition or obesity were thought to affect a large proportion of the refugee population. It appeared that while some of these diseases may have been in place before the refugees arrived in the U.S., the diet they were becoming accustomed to was aggravating these conditions.

If we didn't come to the United States, some of us would have died already... when we come here people began to discovered a lot of different diseases that you have never been aware of before...you never knew that you are diabetic. You never knew that you are high blood pressure... I see a lot of high blood pressure from the woman and I think what bring that one to them it may be bad eating habit. (MAA, Former Refugee, 43)

One HCP estimated that among the resettled refugees that visit her facility, the prevalence of diabetes was high and could be partly attributed to their native cuisine.

We have a huge ridiculous amount of diabetics here at our center. I would say almost $50 \%$ of our clients are diabetic. A lot of that has to do with the cultural diet that they like to eat. $(H C P, 31)$

Factors Possibly Influencing Nutrition-Related Health Concerns

\section{Influence of Prior Habits on Present Nutrition}

Many explanations were offered that linked previous experiences of refugees to their eating habits years later.

Many of them are starved...in their past...so when they do have food, they will eat until they literally 
explode, not literally figuratively of course...I've seen it here. $(H C P, 31)$

The kinds of foods consumed were as equally influential on nutritional status as was the amount of food being eaten. Participants recognized that in the past a lack of healthy food options had forced refugees to eat poorly, which appeared to be shaping their habits and choices post-resettlement.

When you are a refugee... you eat whatever you find, so that's what is causing bad eating... they don't watch healthy food, they will just eat fat, the sugar that is the problem. (Refugee of African origin, 33)

\section{Acculturation}

Many participants described a devolution of eating habits over the course of resettlement.

Q. How do you think they compare to the rest of the US population?

A. Their diet might be better because more of them, first the population would have a mom at home, or grandma at home, or an aunty... who cooks, prepares more meals that are ...healthier than fast foods. It might be better nutritionally for the first years that they are here and digresses later on the American diet, which is of most, not too healthy. (MAA, 25)

Most participants also believed that children's food choices were being influenced by American culture and their peers.

The kids get affected by lack of fresh healthy foods, by the stress as well, and just by the overwhelming American society... So the kids, they get pulled by the allure and all the neon colors and 'please, please, please'... there's already that social pressure. You already have the natural pull to individuate... (HCP, 42)

Concern was expressed over the eating habits of refugee children and teenagers in that many enjoyed food that was high in calories and low in nutritional value, such as "fast food."

They like outside food more than their food when they start integrated... and that is a big concern to moms, the parents in the house. This is the food we are brought up with, how come now you don't like it. (MAA, Former Refugee, 47)

\section{Socio-Economic Status and Neighborhood Factors}

Neighborhood characteristics and the reality that refugees commonly struggle economically for years post- resettlement were offered as possible reasons for poor food choices among this population. Many participants mentioned having multiple jobs to earn enough money to support their families, and others mentioned money being tight.

They get to the US and they're eating fast food, which they may not have access to a kitchen, they may not have money to buy groceries ahead of time and they have to sort of eat from their pocket... so fresh, healthy food can be really hard to come by when you're very poor. $(H C P, 42)$

Most recent refugee arrivals to San Diego settle in just a few neighborhoods, driven in part by lower rents and a desire to be close to those with a similar background. Compared to San Diego County overall, one neighborhood common to refugees has a higher residential density (18 housing units per residential area vs. 3), and a higher percentage of the population living below the poverty line (38 vs. 12\%) [14]. Participants often described the neighborhood environment in which refugees live as negatively affecting physical exercise and likely contributing to weight gain in these populations.

Usually the housing...conditions that they live in, you know they just can't go outside and play by themselves.... kids are more sedentary now... and it's the parents, they think it's safer because they're not outside you know exposed to all these ... crimes and problems and gangs and things that, that we have in this community. (HCP, 47)

\section{Lack of Food Choice Familiarity and Nutritional Knowledge}

A lack of availability of the types of foods refugees were accustomed to in their native country, and a lack of knowledge of foods available in the US appeared to contribute to the poor food choices among the refugees. A few participants mentioned that refugees were uncomfortable with the fact that they were able to obtain fruits and vegetables that were not typically in-season and most had never seen such a large variety of food in their lifetimes.

I don't think that refugees are familiar [with] the kind of you know different foods that they...need to get for example. They may go to just a local market and get you know some of the things that are familiar. (MAA, Former Refugee, 38)

\section{Health Promotion Solutions}

Culturally and linguistically appropriate educational approaches were the most commonly offered solution for 
promoting health among the refugee populations in San Diego. Classes, workshops and seminars held by trusted community leaders in locations where refugees gather were suggested as ways to distribute information and teach refugees about their health.

Probably health education...going to the communities like in mosques...schools, madrasas ...churches where they have only those refugees who have a common religion go together, these kind of places.... Education is very effective. (VOLAG, Former Refugee, 47)

\section{Discussion}

Our study suggests that refugees in their early post-resettlement years continue to face nutritional challenges. It appears that resettled refugees may be becoming accustomed to poor eating habits. This was reported to lead to excessive weight gain and possibly associated sequelae. Additionally, nutritional deficiencies were reported to continue to affect this population. Eating habits, both preexisting and newly acquired, a lack of knowledge, and a low socio-economic status all emerged as likely contributing factors to the nutritional health of the resettled refugee population in San Diego County.

Our study suggests that a history of food shortages as a refugee may be associated with overeating when food became more widely available. It also appears that becoming accustomed to an American lifestyle, including consumption of calorie-dense, nutrient-poor foods and lower levels of physical activity, is causing substantial weight gain in this population, especially among youth. Children were reported to request what they observed their peers eating or food items that were advertised on television. Children in the US are directly targeted by advertisers of food products through multiple media sources, and the majority of food advertisements are for foods that are high in calories, fat or sugar [15-18].

Participants suggested that undernutrition in this population resulted not from food shortages, but logistical and other barriers to nutritious foods. Refugees were reported to be making unhealthy food choices including the consumption of substantial quantities of prepared foodsespecially "fast foods" - which tend to be high in calories but low in nutritional value [15]. Other qualitative studies examining nutrition among African refugees and asylum seekers in the U.S. and Switzerland found participants to eat less fruits and vegetables and more prepared foods upon arrival to their host country due to price, taste, familiarity and preparation $[19,20]$.

The lower socioeconomic status of resettled refugees in San Diego appeared to have a negative effect on their nutrition, based on participants' reports. Lack of time and money may lead to a decrease in food preparation at home and an increase in meals eaten away from home. Unhealthy food choices, including increased consumption of prepared foods, have been previously associated with lower income [21]. Participants of one qualitative study conducted among a population of low- to moderate-income adults in an urban upstate New York community felt that longer work hours, overtime, shift work, and inflexible schedules gave them a feeling of a lack of time and energy to prepare meals at home, leading to an increase in the consumption of unhealthy foods [22].

The study participants expressed concern over refugee weight gain post-resettlement. Unsafe community conditions were perceived as contributing to physical inactivity; this association has been reported elsewhere [23-25]. Epidemiological and animal model studies have linked prenatal nutrient restriction, such as commonly seen in refugee camps [26], with becoming overweight later in life if food becomes plentiful; they suggest that the body is preprogrammed during gestation to survive in a malnourished state after birth, so when fed large amounts of high calorie food, they gain weight very easily [27-30]. This phenomenon might be a factor in the perceived rapid post-resettlement weight gain among some refugees in this region and warrants further investigation.

Rates of diseases that are commonly nutritionally influenced (e.g. diabetes, heart disease, high blood pressure, and obesity) have been found to increase linearly with the length of time that immigrants reside in the US and other host countries [31-34]. Our participants' indicated that in some cases such diseases may have been present before arrival to the US, but were not commonly identified until after arrival, possibly due to increased healthcare access. Prenatal nutrient restriction has also been linked to increased rates of chronic diseases later in life [30, 35]. Further research is needed to confirm time and location of disease development, and etiology of these diseases needs to be more thoroughly examined among refugee populations.

Due to the qualitative study design, resource and time restrictions, our sample size was limited. However, qualitative studies provide valuable insight that is not necessarily revealed in larger, quantitative studies and may help to inform future assessments and interventions. The results of our study cannot be generalized to other populations of resettled refugees nor can it denote nutritional challenges among specific ethnic groups. However, many of the nutrition themes identified appear to be common concerns of resettled groups [6, 19, 20, 24, 34]. Because all HCP participants regularly see refugee populations, their views may differ from those of other HCPs who do not commonly see such clients. Our study is also limited in that nutritional terms such as "overweight" may have meant 
different things to participants. Interviewers were instructed to probe regarding such general clinical terms and such outcomes were only included in the results if they repeatedly emerged as themes.

Refugee serving organizations in San Diego have recently begun to pilot several small programs intended to increase knowledge and access to nutritional food items, including starting a farmers market in a neighborhood where many resettled refugees live and introducing food literacy programs at schools. Further research into nutritional concerns of refugees recently resettled in the US is needed to tailor current nutritional programs to better meet refugee health needs.

Eating habits, lack of knowledge, and low socio-economic status all appeared to contribute to nutrition-related health concerns and consequences among this population of resettled refugees. Our findings also suggest that a wide range of nutritional health issues and related conditions may be affecting San Diego refugees, from nutritional deficiencies to weight gain. Educational interventions, such as culturally-sensitive and language-appropriate classes and workshops that can help to educate refugees on nutritious food items, food preparation, and how nutrition affects health, may all be practical approaches to assist in the development of better dietary habits and may help to improve the health outcomes and quality of life of refugee populations in the US.

Acknowledgments We sincerely thank the study participants who gave their time and shared their opinions, beliefs, and experiences. We gratefully acknowledge the help of the San Diego Refugee Forum, and refugee community members. Many thanks to the interpreters and interviewers who made this assessment possible. The work was funded by the County of San Diego Health and Human Services Agency grant \#06-37-9361-01. There are no conflicts of interest to report by any of the authors.

Open Access This article is distributed under the terms of the Creative Commons Attribution Noncommercial License which permits any noncommercial use, distribution, and reproduction in any medium, provided the original author(s) and source are credited.

\section{References}

1. Jefferys K, Martin D. US Department of Homeland Security Office of Immigration Statistics. Annual Flow Report: Refugees and Asylees, 2007. 2009 vol; 2008.

2. United Nations High Commissioner for Refugees, United Nations Refugee Agency. 2007 Global Trends: Refugees, Asylum-seekers, Returnees, Internally Displaced and Stateless Persons. 2009 vol.

3. San Diego County Health and Human Services Agency, Refugee Health Program. Refugee Data, 2003-2007. 2008.

4. Centers for Disease Control and Prevention. Malnutrition and micronutrient deficiencies among Bhutanese refugee childrenNepal, 2007. MMWR Morb Mortal Wkly Rep. 2008;57:370-3.
5. Geltman PL, Radin M, Zhang Z, Cochran J, Meyers AF. Growth status and related medical conditions among refugee children in Massachusetts, 1995-1998. Am J Public Health. 2001;91:1800-5.

6. Kemmer TM, Bovill ME, Kongsomboon W, et al. Iron deficiency is unacceptably high in refugee children from Burma. J Nutr. 2003;133:4143-9.

7. United Nations System Standing Committee on Nutrition. United Nations Nutrition Information in Crisis Situations: Report number XVII. 2009 vol; 2008.

8. Vergara AE, Miller JM, Martin DR, Cookson ST. A survey of refugee health assessments in the United States. J Immigr Health. 2003;5:67-73.

9. World Health Organization. Diet, nutrition and the prevention of chronic diseases. 2009 vol; 2003.

10. Morris MD, Popper ST, Rodwell TC, Brodine SK, Brouwer KC. Healthcare Barriers of Refugees Post-Resettlement. J Commun Health. 2009;34:529-38.

11. San Diego Refugee Forum Interest Survey: San Diego Refugee Forum, 2005-2006, San Diego, CA; 2006.

12. Strauss A, Corbin J. Basics of qualitative research: techniques and procedures for developing grounded theory. 2nd ed. Thousand Oaks: Sage Publications; 1998.

13. Office for the High Commissioner for Human Rights. The United Nations. Convention Relating to the Status of Refugees.

14. San Diego Association of Goverments (SANDAG). Demographics and Other Data: Data Warehouse. 2009.

15. Paeratakul S, Ferdinand DP, Champagne CM, Ryan DH, Bray GA. Fast-food consumption among US adults and children: dietary and nutrient intake profile. J Am Diet Assoc. 2003;103:1332-8.

16. Powell LM, Szczypka G, Chaloupka FJ. Adolescent exposure to food advertising on television. Am J Prev Med. 2007;33:S251-6.

17. Shifrin DL, Broughton DD, Buttross S, et al. Children, adolescents, and advertising. Pediatrics. 2006;118:2563-9.

18. Taras HL, Gage M. Advertised foods on children's television. Arch Pediat Adol Med. 1995;149:649-52.

19. Kruseman M, Barandereka N-A, Hudelson P, Stalder H. Postmigration dietary changes among African refugees in Geneva: a rapid assessment study to inform nutritional interventions. Soz Praventiv Med. 2005;50:161-5.

20. Willis MS, Buck JS. From Sudan to Nebraska: Dinka and Nuer refugee diet dilemmas. J Nutr Educ Behav. 2007;39:273-80.

21. Block JP, Scribner RA, DeSalvo KB. Fast food, race/ethnicity, and income-A geographic analysis. Am J Prev Med. 2004;27:211-7.

22. Devine CM, Connors MM, Sobal J, Bisogni CA. Sandwiching it in: spillover of work onto food choices and family roles in lowand moderate-income urban households. Soc Sci Med. 2003;56:617-30.

23. Carver A, Timperio A, Crawford D. Playing it safe: the influence of neighbourhood safety on children's physical activity-a review. Health Place. 2008;14:217-27.

24. Guerin PB, Diiriye RO, Corrigan C, Guerin B. Physical activity programs for refugee Somali women: working out in a new country. Women Health. 2003;38:83-99.

25. Wilson DK, Kirtland KA, Ainsworth BE, Addy CL. Socioeconomic status and perceptions of access and safety for physical activity. Ann Behav Med. 2004;28:20-8.

26. United Nations High Commissioner for Refugees, United Nations Refugee Agency. UN agencies highlight dangers of increasing malnutrition in refugee camps. 2009 vol.

27. Budge H, Gnanalingham MG, Gardner DS, Mostyn A, Stephenson T, Symonds ME. Maternal nutritional programming of fetal adipose tissue development: long-term consequences for later obesity. Birth Defects Res C Embryo Today. 2005;75:193-9.

28. Desai M, Gayle D, Babu J, Ross MG. Programmed obesity in intrauterine growth-restricted newborns: modulation by newborn 
nutrition. Am J Physiol Regul Integr Comp Physiol. 2005;288: R91-6.

29. Ravelli AC, van Der Meulen JH, Osmond C, Barker DJ, Bleker OP. Obesity at the age of $50 \mathrm{y}$ in men and women exposed to famine prenatally. Am J Clin Nutr. 1999;70:811-6.

30. Roseboom T, de Rooij S, Painter R. The Dutch famine and its long-term consequences for adult health. Early Hum Dev. 2006;82:485-91.

31. Goel MS, McCarthy EP, Phillips RS, Wee CC. Obesity among US immigrant subgroups by duration of residence. JAMA. 2004;292:2860-7.

32. Mooteri SN, Petersen F, Dagubati R, Pai RG. Duration of residence in the United States as a new risk factor for coronary artery disease (The Konkani heart study). Am J Cardiol. 2004;93:359-61.
33. Palinkas LA, Pickwell SM, Brandstein K, et al. The journey to wellness: stages of refugee health promotion and disease prevention. J Immigr Health. 2003;5:19-28.

34. Renzaho AMN, Gibbons C, Swinburn B, Jolley D, Burns C. Obesity and undernutrition in sub-Saharan African immigrant and refugee children in Victoria, Australia. Asia Pac J Clin Nutr. 2006;15:482-90.

35. Ravelli ACJ, van der Meulen JHP, Michels RPJ, et al. Glucose tolerance in adults after prenatal exposure to famine. Lancet. 1998;351:173-7. 